\title{
Genetic Variability, Heritability, Genetic Advance, and Correlation Analysis in F2 Segregating Population of Tomato (Solanum lycopersicum L.).
}

\author{
I. A. Al-Ballat and A. A. Al-Araby \\ Horticulture Department, Faculty of Agriculture, Tanta University, 31527, Tanta, Egypt. \\ Corresponding author: asem_alaraby@agr.tanta.edu.eg
}

\begin{abstract}
Tomato is one of the most important vegetable crops grown in Egypt. We aimed to investigate the genetic variability parameters, heritability, genetic advance, and correlation coefficient analysis for some important traits. Therefore, we evaluated the cross Ms $35 \times \mathrm{I}-4$, along with its parents and $\mathrm{F}_{2}$ generation, at Ad-Daljamun village, Kafr El-Zayat, Egypt, during the 2017 summer season. High genotypic coefficient of variation (GCV) was found for average fruit weight, number of fruits per plant, and weight of fruits per plant. Heritability in broad sense was very high for number of fruits per truss, number of days to $50 \%$ mature fruits, average fruit weight, total soluble solids content, number of fruits per plant, and weight of fruits per plant. The genetic advance as percentage of the mean (GA\%) was high for number of flowers per inflorescence, number of fruits per truss, average fruit weight, number of fruits per plant, and weight of fruits per plant. Generally, average fruit weight, number of fruits per plant, and weight of fruits per plant, had high values of genotypic coefficient of variation, heritability, and GA\%, therefore, they are important for the direct selection. The correlation coefficient analysis indicated a high association between weight of fruits per plant and average fruit weight, also, between number of fruits per plant and each of number of inflorescences per plant, number of flowers per inflorescence, and number of fruits per truss. Moreover, a high correlation was found between number of flowers per inflorescence and number of fruits per truss.
\end{abstract}

Keywords: Coefficient of variation; Phenotypic correlation; Genotypic correlation; Selection intensity; selection differential.

\section{Introduction}

Tomato (Solanum lycopersicum $L$.), $(2 \mathrm{n}=2 \mathrm{x}=24)$ is one of the most important vegetables grown in the world as the harvested area was 4.8 million hectares with a total production of 182.3 million tonnes. In Egypt, it is grown on 182.44 thousand hectares with an annual production of 7.30 million tonnes (FAOSTAT, 2017). It is grown for both fresh market and processing purposes

Genetic improvement of a crop depends on the genetic variability, either naturally existed in the population or created by the plant breeder. Therefore, the phenotypic coefficient of variation (PCV) and genotypic coefficient of variation (GCV) are useful parameters to detect the variability in a population. Moreover, the genetic component of a trait is the only portion of variation that can be transferred to the subsequent generation. The ratio of genotypic variance to the phenotypic variance is referred to as heritability which represents the heritable part of variation (Singh, 2001). The heritability has a predictive role that determines how much the phenotypic can express the genotypic value of a quantitative trait (Falconer, 1981).

Estimates of heritability alone could not give a reliable parameter for the response to selection. Therefore, heritability estimates in conjunction with the genetic advance, are more useful in predicting the genetic advance under selection (Johnson et al., 1955). Also, the correlation coefficient among various economic traits that affect fruit yield, helps to identify the most important traits that can serve as selection criteria.

Many researchers investigated the genetic parameters and correlation among economic traits in different breeding schemes of tomato and reported various recommendations about the utilization for such information to develop new genotypes with desirable traits (Ghosh et al., 2010; Sidhya et al., 2014; Bhandari et al., 2017; and Singh and Singh, 2018).

Limited information is available with respect to the variability parameters on tomato under Egyptian conditions. Moreover, imported hybrids of tomato are predominant in the local market of Egypt. Thus, it is required to develop superior local genotypes. Accordingly, the objective of this study was to estimate the phenotypic and genotypic variability, heritability, and genetic advance expected under selection, as well as, the phenotypic and genotypic correlation coefficients among important traits of tomato grown in the summer season under the Middle of Nile Delta region in Egypt.

\section{Materials and methods}

Plant materials and experiment management

We initiated this study with two accessions of tomato (Solanum lycopersicum L.) one of them is Ms35 whereas the other accession (I-4), was previously selected by the first author from $\mathrm{F}_{3}$ generation of a cross between LYC 3019 and LYC 3194. The original parental accessions were 
obtained from the Leibniz Institute of Plant Genetics and Crop Plant Research (IPK). The two accessions (Ms35 and I-4) were intercrossed in March 2016 to obtain the $F_{1}$ cross. In October 2016, The $F_{1}$ seeds were cultivated and selfed to produce $F_{2}$ seeds. In the summer season of 2017 , all four populations, Viz., $\mathrm{P}_{1}, \mathrm{P}_{2}, \mathrm{~F}_{1}$, and $\mathrm{F}_{2}$ were cultivated at AdDaljamun village, Kafr El-Zayat city, El-Gharbia Governorate, Egypt. Ad-Daljamun is located at a latitude of $30^{\circ} 48^{\prime} 34^{\prime \prime}$ and longitude of $30^{\circ} 50^{\prime} 3^{\prime \prime}$. The loamy soil was the predominant soil type.

The genotypes were sown at the nursery on $26^{\text {th }}$ April 2017 and transplanted into the field on $20^{\text {th }}$ May 2017. The plants were kept at $40 \mathrm{~cm}$ plant to plant and $100 \mathrm{~cm}$ row to row distance, with one plant per hill. Also, they were bred vertically and supported with wooden stalks. According to the limited available area for the experiment, we evaluated five plants from each of parent 1 , parent 2 and their $F_{1}$ cross due to their homogeneity. While $\mathrm{F}_{2}$ population was represented by 210 plants.

Eleven quantitative agronomic traits were evaluated for each plant, according to the International Plant Genetic Resources Institute descriptors for Tomato (IPGRI, 1996) with some modifications. Data were taken after 45 days from transplanting for vegetative traits as follows; Plant height $(\mathrm{cm})$, measured from the soil surface to the tip of the longest stem of a plant; number of nodes per plant, counted on the main stem; node length $(\mathrm{cm})$, measured with a measuring tab in a centimeter.

Concerning flowering, yield, and fruit traits, data were taken after 70 days from transplanting on $2^{\text {nd }}$, $3^{\text {rd }}, 6^{\text {th }}$, and $9^{\text {th }}$ inflorescences to represent various stages of plant growth. Accordingly, number of inflorescences per plant, counted on the main stem; number of flowers per inflorescence, counted on the four inflorescences and recorded as an average; number of fruits per truss, averaged over the four trusses; number of days to $50 \%$ mature fruits, counted from sowing until $50 \%$ of plants have at least one ripened fruit; average fruit weight $(\mathrm{g})$, calculated as an average of 10 fruits per plant, total soluble solids content (TSS\%), measured in Brix unit from two juice samples each consisted of mixing juices of five fruits; number of fruits per plant, calculated by multiplying the number of inflorescences per plant $x$ average number of fruits per truss; and weight of fruits per plant, calculated by multiplying the number of inflorescences per plant $\times$ average number of fruits per truss $\times$ average fruit weight.

\section{Statistical analyses}

The coefficient of range was calculated according to the following formula:

Coefficient of range $=($ Max.-Min. $) /($ Max. + Min. $)$

Where, Max. is the highest value of the trait and Min. is the lowest one.
The environmental variance $(\mathrm{Ve})$ was calculated as $\mathrm{Ve}=\left(\mathrm{Vp}_{1}+\mathrm{Vp}_{2}+2 \mathrm{VF}_{1}\right) / 4$, where $\mathrm{VP}_{1}, \mathrm{VP}_{2}$, and $\mathrm{VF}_{1}$, is the the variances of parent 1 , parent 2 , and the cross between them, respectively.

The Phenotypic (PCV) and genotypic (GCV) coefficients of variation were calculated according to the formula suggested by Singh and Chaudhary (1985) as

$$
\begin{aligned}
& \operatorname{PCV}(\%)=(\sigma \mathrm{p} / \overline{\mathrm{X}}) \times 100 \\
& \operatorname{GCV}(\%)=(\sigma \mathrm{g} / \overline{\mathrm{X}}) \times 100
\end{aligned}
$$

Where, $\sigma \mathrm{p}, \sigma \mathrm{g}$, and $\overline{\mathrm{X}}$ are the phenotypic standard deviation, genotypic standard deviation, and the grand mean of the trait, respectively.

Broad sense heritability $\left(\mathrm{h}^{2}\right.$ b.s. $)$ estimate of each trait was calculated according to Falconer (1981) as: $\mathrm{h}^{2}$ b.s. $=\mathrm{GV} / \mathrm{PV}$

Where $\mathrm{h}_{\text {b.s. }}^{2}$ is the broad-sense heritability, $\mathrm{GV}$ is the genetic variance, and PV is the total phenotypic variance.

We adopted $20 \%$ as selection intensity to keep an adequate level of variability among selected individuals to agree with the long-term selection strategies. The Expected genetic advance was estimated according to the method outlined by Johnson et al. (1955) as follows:

Expected genetic advance $(\mathrm{GA})=\mathrm{K} \times \sigma \mathrm{p} \times \mathrm{h}^{2}{ }_{\mathrm{b} . \mathrm{s}}$. where $\mathrm{GA}$ is the genetic advance, $\mathrm{K}$ is a constant = 1.4 at $20 \%$ selection intensity, $\sigma p$ is the square root of phenotypic variance, and $\mathrm{h}_{\text {b.s. }}^{2}$ is the heritability in the broad sense.

GA as a percentage of the mean $(\mathrm{GA} \%)=$ $(\mathrm{GA} / \overline{\mathrm{X}}) \times 100$; where $\overline{\mathrm{X}}$ is the mean of the trait in the base population.

The analyses of phenotypic, genotypic and environmental correlations were estimated according to Miller et al. (1958) as follows:

$r P_{x y}=\frac{\operatorname{covp} p_{x y}}{\sqrt{\mathrm{vp}_{\mathrm{x}} \cdot \mathrm{vp}_{\mathrm{y}}}}$
$r g_{x y}=\frac{\operatorname{cov} g_{x y}}{\sqrt{\mathrm{vg}_{\mathrm{x}} \cdot \mathrm{vg}_{\mathrm{y}}}}$

Where $\operatorname{rp}_{\mathrm{xy}}=$ phenotypic correlation coefficient between traits $\mathrm{x}$ and $\mathrm{y}$.

$\operatorname{covp}_{\mathrm{xy}}=$ phenotypic covariance between traits $\mathrm{x}$ and y.

$v p_{x}, v p_{y}=$ phenotypic variance of a trait $\mathrm{x}$ and a trait $\mathrm{y}$, respectively.

$\mathrm{rg}_{\mathrm{xy}}=$ genotypic correlation coefficient between traits $\mathrm{x}$ and $\mathrm{y}$.

$\operatorname{covg}_{\mathrm{xy}}=$ genotypic covariance between traits $\mathrm{x}$ and y.

$\mathrm{vg}_{\mathrm{x}}, \mathrm{vg}_{\mathrm{y}}=$ genotypic variance of a trait $\mathrm{x}$ and a trait $\mathrm{y}$, respectively.

The significance of the correlation coefficients was tested at the probability levels of 0.05 and 0.01 using t test at $n-2$ degrees of freedom according to the following equation:

$\mathrm{t}=r \times \sqrt{\frac{n-2}{1-r^{2}}}$ 
where $\mathrm{r}$ is the correlation coefficient, and $\mathrm{n}$ is the number of $F_{2}$ individuals in the case of phenotypic correlation coefficient. Whereas for environmental correlation coefficient, the degrees of freedom will be n'-2, where n' is the average number of individuals from the generations used to estimate the environmental variance $\left(\mathrm{P}_{1}, \mathrm{P}_{2}\right.$, and $\left.\mathrm{F}_{1}\right)$. For the genotypic correlation coefficient, the degrees of freedom will be n' -2 , where n' is the average between $\mathrm{n}$ and $\mathrm{n}$ '. (Cruz, Personal communication). GENES software (Cruz, 2016) was adopted to analyze all data of the study.

\section{Results and discussion}

\section{Genetic variability and heritability}

The range was maximum for average fruit weight (156.00), plant height (124.00), and number of fruits per plant (94.33), respectively, while TSS and number of inflorescences per plant had the lowest ones. In this regard, Bhandari et al. (2017), and Golani et al. (2007), found maximum range for number of fruits per plant, average fruit weight, and plant height. However, the range is a weak measure of dispersion. The maximum coefficient of range was recorded for weight of fruits per plant (0.76), average fruit weight (0.67), number of fruits per plant (0.65), number of fruits per truss $(0.60)$, and number of flowers per inflorescence $(0.55)$. This indicates that, these traits had a greater dispersion of variation. In this concern, Bhandari et al. (2017) reported similar results.

The phenotypic variance was greater than the genotypic variance for all traits, with the maximum values were reported for average fruit weight, plant height, and number of fruits per plant.

The estimates of phenotypic (PVC) and genotypic (GCV) coefficients of variation are considered high if they are greater than $20 \%$, whereas those between $10 \%$ and $20 \%$ are regarded as medium, and values less than $10 \%$ to be low (Deshmukh et al., 2005). Consequently, weight of fruits per plant $(39.66 \%$ and $38.72 \%)$, number of fruits per plant $(26.79 \%$ and $25.06 \%$ ), and average fruit weight (31.97 and \%31.58\%), had high PCV and high GCV (> 20\%), respectively (Table 1). While number of flowers per inflorescence $(22.56 \%$ and $18.11 \%)$, and number of fruits per truss $(21.70 \%$ and $19.71 \%$ ) had high PCV and medium GCV, suggesting the environmental effect on the expression of such traits. Whereas, the other traits had medium values $(<10 \%)$ of both PCV and GCV. On the contrary, number of days to $50 \%$ mature fruits, showed low values of both PCV and GCV.

High GCV values suggest the possibility of improving these traits through genetic manipulations such as selection. In general, the differences between PCV and GCV were low for all traits, indicating a low influence of the environment, which suggests the possibility to genetically improve such traits.

All traits exhibited slightly higher PCV values than GCV, suggesting the minor effect of the environment on the expression of the traits, indicating the reliability of the selection based on these traits. Concerning number of days to $50 \%$ mature fruits, it had an equal estimate of PCV and $\mathrm{GCV}$, suggesting that it is almost totally controlled with the genetic effects. In this concern, Chernet et al. (2013) agree with our results since they found high values of PCV and GCV for plant height, number of inflorescences per plant, number of flowers per inflorescence, number of fruits per plant, weight of fruits per plant, and average fruit weight. While, they obtained medium values of both PCV and GCV for number of days to $50 \%$ mature fruits and TSS.

Table 1. Mean, range, coefficient of range, phenotypic variance (PV), genotypic variance (GV), phenotypic coefficient of variation (PCV), genotypic coefficient of variation (GCV), and broad-sense heritability $\left(\mathrm{h}_{\text {b.s. }}^{2}\right)$ for eleven traits of $\mathrm{F}_{2}$ segregating population of the cross combination Ms $35 \times \mathrm{I}-4$ of tomato (Solanum lycopersicum L.) plants, grown at Ad-Daljamun village, El-Gharbia Governorate, Egypt, during the summer season of 2017.

\begin{tabular}{|c|c|c|c|c|c|c|c|c|}
\hline Traits & Mean & $\begin{array}{l}\text { Range } \\
\text { (Maximum-minimum) }\end{array}$ & $\begin{array}{l}\text { Coefficient } \\
\text { of range }\end{array}$ & PV+S.D. & GV+S.D. & $\mathrm{h}_{\text {b.s. }}^{2}+$ S.D. & PCV & $\mathrm{GCV}$ \\
\hline$\overline{\mathrm{PH}}$ & 124.85 & $188.00-64.00$ & 0.49 & $429.64+42.03$ & $340.94+46.20$ & $79.36+3.54$ & 16.60 & 14.79 \\
\hline NNPP & 17.38 & $24.00-9.00$ & 0.45 & $11.08+1.08$ & $6.73+4.38$ & $60.73+121.04$ & 19.15 & 14.92 \\
\hline ANL & 7.29 & $14.33-5.18$ & 0.47 & $1.24+0.12$ & $0.87+0.39$ & $70.26+727.60$ & 15.30 & 12.83 \\
\hline NIPP & 8.39 & $11-6$ & 0.29 & $1.06+0.10$ & $0.81+0.27$ & $76.42+1443.86$ & 12.27 & 10.73 \\
\hline NFLPI & 9.64 & $17.0-4.880$ & 0.55 & $4.73+0.46$ & $3.05+1.73$ & $64.45+181.41$ & 22.56 & 18.11 \\
\hline NFRPT & 8.69 & $14.67-3.67$ & 0.60 & $3.56+0.35$ & $2.94+0.71$ & $82.51+400.46$ & 21.70 & 19.71 \\
\hline NDMF & 89.54 & $101.00-79.00$ & 0.12 & $16.85+1.65$ & $16.85+1.65$ & $99.99+87.23$ & 4.58 & 4.58 \\
\hline AFW & 111.63 & $195.00-39.00$ & 0.67 & $1273.46+124.57$ & $1242.64+125.24$ & $97.58+0.81$ & 31.97 & 31.58 \\
\hline TSS & 6.93 & $8.50-5.00$ & 0.26 & $0.68+0.07$ & $0.65+0.07$ & $95.15+1610.36$ & 11.93 & 11.63 \\
\hline NFPP & 73.47 & $120.00-25.67$ & 0.65 & $387.41+37.90$ & $338.92+41.50$ & $87.49+3.41$ & 26.79 & 25.06 \\
\hline WFPP & 8.09 & $17.64-2.38$ & 0.76 & $10.28+1.01$ & $9.80+1.12$ & $95.30+136.20$ & 39.66 & 38.72 \\
\hline
\end{tabular}

S.D. of PV, EV, GV, and $\mathrm{H}^{2}$ b.s. were calculated with the bootstrap method (Efron, 1979) with 1000 simulations.

PH: Plant height, NNPP: number of nodes per plant, ANL: average node length, NIPP: number of inflorescences per plant, NFLPI: number of flowers per inflorescence, NFRPT: number of fruits per truss, NDMF: number of days to $50 \%$ mature fruits, AFW: average fruit weight, TSS: Total soluble solids content, NFPP: number of fruits per plant, and WFPP: weight of fruits per plant. 
Also, Sidhya et al. (2014) found medium PCV and GCV for plant height, while, in contrast to our findings, they reported medium PCV and GCV for number of fruits per plant and weight of fruits per plant. Singh and Singh (2018) agree with our results for plant height, number of fruits per truss, average fruit weight, number of fruits per plant, weight of fruits per plant, and TSS. Moreover, Saravanan et al. (2019) found high PCV and GCV for number of fruits per plant.

Heritability in its broad sense, ranged from $60.73 \%$ for number of nodes per plant to $99.99 \%$ for number of days to $50 \%$ mature fruits. The heritability estimates were very high for number of fruits per truss $(82.51 \%$ ), number of days to $50 \%$ mature fruits $(99.99 \%)$, average fruit weight (97.58\%), TSS (95.15), number of fruits per plant $(87.49 \%)$, and weight of fruits per plant $(95.30 \%)$. Whereas, it ranged from moderate to high for the other traits. The selection would be easy for traits with very high heritability values $(>80 \%)$ as a result of smaller effect of the environment, while for low values of heritability $(<40 \%)$, the selection would be difficult (Singh, 2001). Consequently, the selection might be fruitful for all traits under study, in particular, those with very high heritability estimates.

In this regard, Hidayatullah et al. (2008) reported high heritability for plant height, number of fruits per plant, fruit weight per plant, average fruit weight, and TSS. Also, Mehta and Asati (2008) found high heritability for plant height, number of trusses per plant, weight of fruits per plant, and TSS. Bhandari et al. (2017) reported very high heritability estimates for all traits. Moreover, our results agree with those obtained by Singh and Singh (2018), as they reported high heritability estimates for plant height, average fruit weight, TSS, number of fruits per plant, and weight of fruits per plant. On the contrary to our results, they found low heritability estimates for number of fruits per truss.

\section{Genetic advance}

Genetic advance under selection represents the magnitude of the predicted improvement that could be obtained in the selected individuals over their base population (Singh, 2001). The genetic advance as percent of mean $(\mathrm{GA} \%)$ at $20 \%$ selection intensity, was high (> 20\%) for weight of fruits per plant $(52.91 \%)$, average fruit weight $(43.67 \%)$, number of fruits per plant $(32.81 \%)$, number of fruits per truss $(25.06 \%)$, and number of flowers per inflorescence $(20.36 \%$ ) (Table 2). High estimates of GA\% suggest the predominance of additive gene effects, thus, selection would be successful for improving such traits.

Number of days to $50 \%$ mature fruits, and TSS had high heritability estimates $(99.99 \%$ and $95.15 \%)$ and low GA\% (6.42\% and $15.89 \%)$, respectively. This indicates the influence of non-additive gene action and considerable effect of the environment on these traits. Accordingly, they might be improved through utilization of heterosis. Our results agree with the findings of Pradeepkumar et al. (2001) who reported high GA\% for plant height, number of fruits per plant, fruit weight, and fruit yield per plant. Similarly, Golani et al. (2007) obtained high GA\% for average 10 fruits weight.

Also, Ghosh et al. (2010) found high genetic advance for number of fruits per plant, fruit yield per plant, and number of fruits per truss. Bhandari et al. (2017) found high estimates of GAM (>60) for average fruit weight, fruit yield per plant, and number of fruits per plant. Moreover, Singh and Singh (2018) agree with our findings for average fruit weight, number of fruits per plant, and weight of fruits per plant. While they found; high GA\% for plant height, and TSS; and low GA\% for number of fruits per truss.

Table 2. Means of the selected individuals $\left(\bar{X}_{S}\right)$, genetic advance (GA), genetic advance as percentage of mean $(\mathrm{GA} \%)$, and expected mean for the first cycle after selection $\left(\mathrm{e}_{\mathrm{S} 1}\right)$, for eleven traits of $\mathrm{F}_{2}$ segregating population of the cross combination Ms35 $\times$ I-4 of tomato (Solanum lycopersicum L.) plants, grown at Ad-Daljamun village, El-Gharbia Governorate, Egypt, during the summer season of 2017.

\begin{tabular}{lllll}
\hline Traits & $\overline{\mathrm{X}}_{\mathrm{S}}$ & $\mathrm{GA}$ & $\mathrm{GA} \%$ & $\mathrm{e}$ \\
\hline Plant height & 150.54 & 23.02 & 18.44 & 147.88 \\
No. of nodes per plant & 21.76 & 2.83 & 16.28 & 20.21 \\
Average node length & 6.14 & 1.10 & 15.05 & 6.192 \\
No. of inflorescences/ Plant & 9.66 & 1.10 & 13.13 & 9.49 \\
No. of flowers/ inflorescence & 12.85 & 1.96 & 20.36 & 11.60 \\
No. of fruits per truss & 11.24 & 2.18 & 25.06 & 10.87 \\
No. of days to 50\% mature fruits & 84.44 & 5.75 & 6.42 & 83.79 \\
Average fruit weight & 161.76 & 48.74 & 43.67 & 160.37 \\
TSS & 8.09 & 1.10 & 15.89 & 8.03 \\
No. of fruits/plant & 100.35 & 24.10 & 32.81 & 97.58 \\
Weight of fruits/plant & 12.95 & 4.28 & 52.91 & 12.36 \\
\hline
\end{tabular}


Generally, weight of fruits per plant, average fruit weight, and number of fruits per plant, had very high heritability, high genetic advance as percent of mean, and high genotypic coefficient of variation, indicating the additive genetic effect. Consequently, such traits could be improved by a simple selection based on phenotypic performance. In this regard, Sidhya et al. (2014) found high heritability estimates coupled with high GA\% for plant height, number of fruits per plant, and fruit weight per plant.

\section{Correlation coefficient analysis}

The genotypic correlations were equal to or higher than the corresponding phenotypic ones for the majority of traits and they had the same signal (Table 3), indicating a minor effect of the environment, which suggests that the selection of such traits would be easy and successful.

According to Al-Ballat and Al-Araby (2019), the correlation coefficient is classified as weak $(<0.50)$, moderate $( \pm 0.50$ to \pm 0.69$)$, strong $( \pm 0.70$ to \pm $0.89)$, or very strong $(> \pm 0.90)$. Based on this classification, weight of fruits per plant showed moderate highly significant positive phenotypic (rf) and genotypic (rg) correlation coefficients with number of fruits per truss, and number of fruits per plant, whereas, it had highly significant positive correlations with strong values $(\mathrm{r} f=0.722$, and $\mathrm{rg}=0.737$ ) with average fruit weight. Number of fruits per plant had highly significant correlation values ranged from weak to moderate with each of plant height, and number of nodes per plant. Whereas, it had highly significant correlations coefficients with number of inflorescences per plant $(\mathrm{rf}=0.633$, and $\mathrm{rg}=0.751)$, number of flowers per inflorescence $(\mathrm{rf}=0.831$, and $\mathrm{rg}=0.922)$, and number of fruits per truss ( $\mathrm{rf}=0.898$, and $\mathrm{rg}=0.929$ ).

Number of fruits per truss had highly significant positive correlations $(\mathrm{rf}=0.910$, and $\mathrm{rg}=0.985)$ with number of flowers per inflorescence Whereas it had highly significant weak or slightly moderate values of correlations with plant height, number of nodes per plant, and number of inflorescences per plant.

Furthermore, number of flowers per inflorescence had highly significant positive correlations with plant height $(\mathrm{rf}=0.430$, and $\mathrm{rg}=$ $0.620)$.

Table 3. Coefficients of phenotypic (rf) and genotypic ( $\mathrm{rg}$ ) correlations in eleven traits of $\mathrm{F}_{2}$ segregating population of the cross combination Ms $35 \times$ I-4 of tomato (Solanum lycopersicum L.) plants, grown at Ad-Daljamun village, El-Gharbia Governorate, Egypt, during the summer season of 2017.

\begin{tabular}{|c|c|c|c|c|c|c|c|c|c|c|c|c|}
\hline & & PH & NNPP & ANL & NIPP & NFLPI & NFRPT & NDMF & AFW & TSS & NFPP & WFPP \\
\hline \multirow{2}{*}{ PH } & $\mathrm{rf}$ & 1 & $0.740 * *$ & $0.192 * *$ & $0.281^{* *}$ & $0.430 * *$ & $0.442^{* *}$ & 0.123 & 0.025 & 0.054 & $0.449^{* *}$ & $0.322 * *$ \\
\hline & $\mathrm{rg}$ & & $0.747 * * *$ & $0.280^{* * *}$ & $0.333^{* *} *$ & $0.620 * *$ & $0.560 * *$ & 0.138 & 0.031 & 0.066 & $0.547 * *$ & $0.380 * *$ \\
\hline \multirow{2}{*}{ NNPP } & $\mathrm{rf}$ & & 1 & $-0.497 * *$ & $0.320^{* *}$ & $0.383 * *$ & $0.391 * *$ & $0.171 *$ & -0.019 & 0.005 & $0.431 * *$ & $0.275 * *$ \\
\hline & $\mathrm{rg}$ & & & $-0.420 * *$ & $0.492^{* *}$ & $0.478 * *$ & $0.478 * *$ & $0.219 *$ & -0.039 & 0.043 & $0.545^{* *} *$ & $0.311 * *$ \\
\hline \multirow{2}{*}{ ANL } & $\mathrm{rf}$ & & & 1 & -0.075 & 0.005 & 0.019 & -0.091 & 0.051 & 0.086 & -0.022 & 0.027 \\
\hline & $\mathrm{rg}$ & & & & $-0.198^{*}$ & $0.212 *$ & 0.158 & -0.109 & 0.074 & 0.072 & 0.041 & 0.101 \\
\hline \multirow{2}{*}{ NIPP } & $\mathrm{rf}$ & & & & 1 & $0.275^{* *}$ & $0.277 * *$ & $0.198 * *$ & $-0.145^{*}$ & 0.058 & $0.663 * *$ & $0.327 * *$ \\
\hline & rg & & & & & $0.484 * *$ & $0.460 * *$ & $0.227^{*}$ & $-0.195 *$ & 0.066 & $0.751 * *$ & $0.333 * *$ \\
\hline \multirow{2}{*}{ NFLPI } & $\mathrm{rf}$ & & & & & 1 & $0.910 * *$ & 0.061 & $-0.223 * *$ & -0.005 & $0.831 * *$ & $0.369 * *$ \\
\hline & $\mathrm{rg}$ & & & & & & $0.985 * *$ & 0.076 & $-0.278 * *$ & -0.046 & $0.922 * *$ & $0.380 * *$ \\
\hline \multirow{2}{*}{ NFRPT } & $\mathrm{rf}$ & & & & & & 1 & 0.063 & -0.125 & 0.007 & $0.898 * *$ & $0.500^{* *}$ \\
\hline & $\mathrm{rg}$ & & & & & & & 0.069 & -0.106 & 0.021 & $0.929 * *$ & $0.522 * *$ \\
\hline \multirow{2}{*}{ NDMF } & $\mathrm{rf}$ & & & & & & & 1 & -0.066 & -0.061 & 0.119 & 0.042 \\
\hline & $\mathrm{rg}$ & & & & & & & & -0.066 & -0.062 & 0.127 & 0.043 \\
\hline \multirow{2}{*}{ AFW } & $\mathrm{rf}$ & & & & & & & & 1 & 0.042 & $-0.167 *$ & $0.722^{* * *}$ \\
\hline & $\mathrm{rg}$ & & & & & & & & & 0.035 & -0.166 & $0.737 * *$ \\
\hline \multirow{2}{*}{ TSS } & $\mathrm{rf}$ & & & & & & & & & 1 & 0.030 & 0.066 \\
\hline & rg & & & & & & & & & & 0.042 & 0.081 \\
\hline \multirow{2}{*}{ NFPP } & $\mathrm{rf}$ & & & & & & & & & & 1 & $0.533^{* *}$ \\
\hline & rg & & & & & & & & & & & $0.520^{* *}$ \\
\hline WFPP & $\mathrm{rf}$ & & & & & & & & & & & 1 \\
\hline
\end{tabular}

*and ** indicate significance at 0.05 and 0.01 levels of probability, respectively against tabulated $\mathrm{t}$ value.

PH: Plant height, NNPP: number of nodes per plant, ANL: average node length, NIPP: number of inflorescences per plant, NFLPI: number of flowers per inflorescence, NFRPT: number of fruits per truss, NDMF: number of days to $50 \%$ mature fruits, AFW: average fruit weight, TSS: Total soluble solids content, NFPP: number of fruits per plant, and WFPP: weight of fruits per plant.

The indirect selection for the traits would be more successful when the correlation coefficient values with the desired trait are higher than 0.50 (Lopes et al., 2002). Accordingly, average fruit weight, number of inflorescences per plant, number of flowers per inflorescence, and number of fruits per truss, could be considered as selection criteria to indirectly select for higher fruit yield expressed as a number, or a weight of fruits per plant.
In this concern, Hlidayatullah et al. (2008) reported positive correlation of fruit yield per plant with number of fruits per plant. Also, Ghosh et al. (2010) found positive correlations for; number of fruits per cluster with number of clusters per plant, number of fruits per plant, and fruit yield per plant; and for number of clusters per plant with number of fruits per plant. 
The results of this study provide better understanding of the genetic parameters that could formulate the basis for future tomato breeding programs. However, there were some possible limitations; according to limited experimental area available for the study, we evaluated five plants from each of $\mathrm{P}_{1}, \mathrm{P}_{2}$, and $\mathrm{F}_{1}$ generations, assuming that, they were totally homogenous. The few number of plants might affect the precise of the environmental variation estimation, and this would be addressed in the future evaluations and selection cycles.

\section{Conclusions}

In this study, we assessed the variability parameters, heritability, genetic advance, and correlation analysis for some economic traits in $\mathrm{F}_{2}$ population derived from the $F_{1}$ cross combination Ms35 $\times$ I-4 of tomato (Solanum lycopersicum L.). The results indicated a wide genetic variability for all traits. In general, weight of fruits per plant, average fruit weight, and number of fruits per plant, had very high heritability, high genetic advance as percent of mean, and high GCV. Therefore, they had the possibility to be improved through the direct selection. There was a high association between, weight of fruits per plant with average fruit weight, and between number of fruits per plant with each of number of inflorescences per plant, number of flowers per inflorescence, and number of fruits per truss. The findings of this study help to select topperforming plants, that would be submitted to further selection cycles to develop improved genotypes suitable for the local environment.

\section{Acknowledgment}

The authors would like to acknowledge Cosme Damiao Cruz, professor at Federal University of Viçosa, for his valuable help and suggestions throughout the statistical analyses of this study. Thanks also are due to the Leibniz Institute of Plant Genetics and Crop Plant Research (IPK) for providing genetic materials.

\section{Funding statements:}

The authors declare that there is no external funding for this study.

\section{Conflicts of interest:}

The authors declare that there are no conflicts of interest related to the publication of this study.

\section{References}

AlBallat, I.; Al-Araby, A., 2019. Correlation and Path Coefficient Analysis for Seed Yield and some of its Traits in Common Bean (Phaseolus vulgaris L.). Egyptian Journal of Horticulture, 46(1), 41-51. doi: 10.21608/ejoh.2018.6481.1088.

Bhandari, H. R.; Srivastava, K.; Reddy, G. E., 2017. Genetic Variability, Heritability and Genetic Advance for Yield Traits in Tomato
(Solanum lycopersicum L.). Int. J. Curr. Microbiol. App. Sci 6, 4131-4138. https://doi.org/10.20546/ijcmas.2017.607.428

Chernet S.; Belew D.; and Abay F., 2013. Genetic Variability and Association of Characters in Tomato (Solanum lycopersicum L.) Genotypes in Northern Ethiopia. International Journal of Agricultural Research, 8 (2): 67-76.

Cruz, C.D., 2016. Genes software - extended and integrated with the R, Matlab and Selegen. Acta Sci., Agron., 38, 547-552. https://doi.org/10.4025/actasciagron.v38i4.32 $\underline{629}$

Deshmukh, S. N.; Basu, M. S.; and Reddy P. S., 2005. Genetic variability, character association and path coefficient analysis of quantitative traits in Viginia bunch varieties of groundnut. Indian J. Agric. Sci., 56: 515-518.

Efron, B., 1979. Bootstrap Methods: Another Look at the Jackknife. The Annals of Statistics, 7 (1): $1-26$.

Falconer, D. S., 1981. Introduction to Quantitative Genetics, second ed. Longman, London. England.

FAOSTAT, 2017. Statistical database of the food and agriculture of the united nations. FAO, Rome, Italy. http://www.fao.org/faostat/en/\#data/QC ( accessed 30.11.2019).

Ghosh, K. P.; Islam A. K. M. A.; Mian M. A.K.; and Hossain M. M., 2010. Variability and character association in $\mathrm{F}_{2}$ segregating population of different commercial hybrids of tomato (Solanum lycopersicum L.). J. Appl. Sci. Environ. Manage. 14: 91-95.

Golani, l. J.; Mehta D. R.; Purohit V. L.; Pandya H. M.; and Kanzariya M.V., 2007. Genetic variability, correlation and path coefficient studies in tomato. Indian J. Agric. Res., 41: 146-149.

Hidayatullah, S.; Jatoi A.; Ghafoor A.; and Mahmood T., 2008. Path coefficient analysis of yield component in tomato (Lycopersicon escuientum). Pak. J. Bot., 40: 627-685.

IPGRI, 1996. Descriptors for Tomato (Lycopersicon spp.), International Plant Genetic Resources Institute, Rome, Italy, pp: 44.

Johnson, H. W.; Robinson, H. F.; and Comstock, R. E., 1955. Estimates of genetic and environmental variability in soybean. Agron. J., 47: 314-318.

Lopes A. C. A.; Vello N.A.; Pandini F.; Rocha M.M.; and Tsutsumi, C. Y., 2002. Variabilidade e correlações entre caracteres emcruzamentos de soja. [Variability and Correlations between 
Characters in Soybean Crosses]. Scientia Agricola, 59 (2), 341-348. (In Portugese).

Mehta, N.; and Asati B. S., 2008. Genetic relationship of growth and development traits with fruit yield in tomato (Lycopersicon esculentum Mill). Karnataka J. Agric. Sci., 21: 92-96.

Miller, P. A.; Williams, J. C.; Robinson, H.F.; and Comstock, R.E., 1958, Estimates of genotypic and environmental variances and covariances in upland cotton and their implications in selection. Agronomy J., 50, 126-131.

Pradeepkumar, T.; Bastian D.; Joy M.; Radhakrishnan N.V.; and Aipe K. C., 2001. Genetic variability in tomato for yield and resistance to bacterial wilt. J. Trop. Agric., 89: 157-158.

Saravanan, K. R.; Vishnupriya V.; Prakash M.; and Anandan R., 2019. Variability, heritability and genetic advance in tomato genotypes. Indian J. Agric. Res., 53:92-95. https://doi.org/10.18805/IJARe.A-5030

Sidhya, P.; Koundinya A. V.V.; and Pandit M. K., 2014. Genetic Variability, Heritability and Genetic Advance in Tomato. Environment \& Ecology 32 (4B): 1737-1740.

Singh, B. D., 2001. Plant Breeding: Principles and Methods. Ludhiana: Kalyani Publishers, New Delhi, India, pp:896.

Singh, H.; and Singh D., 2018. Study on Genetic Variability, Heritability, Genetic Advance and Correlation among different characters in tomato (Solanum lycopersicum L.). IJEAB 3, 1209-1212. https://doi.org/10.22161/ijeab/3.4.8

Singh, R. K.; and Chaudhury B. D., 1985. Biometrical Methods in Quantitative Genetic Analysis. Kalyani Publishers, New Delhi, India, pp: 818.

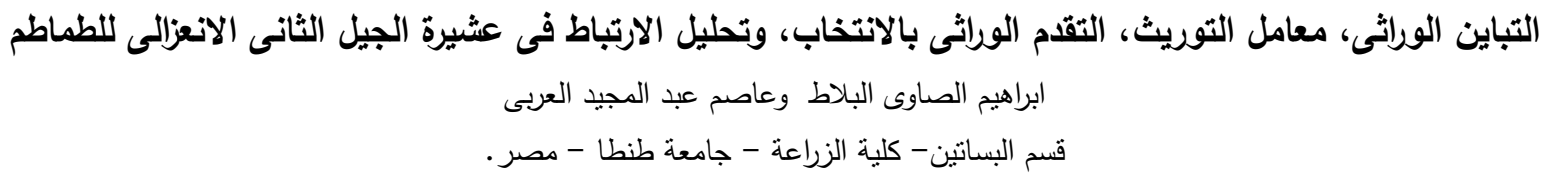

